\title{
EAP Curriculum Alignment and Social Acculturation: Student Perceptions
}

\section{Gregory Tweedie E Marcia Kim}

The role of English as a second language (ESL) teachers and instruction as factors in student social and psychological acculturation is widely acknowledged. However, the function of English for Academic Purposes (EAP) is less well known in this regard, because research has focused largely on academic acculturation. This qualitative study investigated the perceptions of curriculum alignment with undergraduate study by post-EAP learners (students who had successfully completed EAP and were registered in mainstream university programs). Semistructured interviews were conducted with 7 former EAP students from a range of faculties at a large Canadian university. Analysis of interview data highlighted social acculturation as a perceived need in EAP curriculum, as participants remarked on linguistic and cultural barriers faced while participating in university life post-EAP. The researchers argue that social acculturation is typically underrepresented in EAP curriculum, and may be inadvertently overlooked by instructors, curriculum planners, and program providers.

Il est largement reconnu que les enseignants d'anglais langue seconde et l'enseignement linguistique représentent des facteurs importants dans l'acculturation sociale et psychologique des étudiants. Toutefois, on connait moins bien le rôle de l'anglais académique (EAP) dans ce contexte, la recherche ayant surtout visé l'acculturation académique. Cette étude qualitative a interrogé des finissants d'un programme d'anglais académique qui suivaient des cours réguliers à l'université pour connaitre leurs perceptions de l'harmonisation du programme EAP avec les cours réguliers du premier cycle à l'université. Des entrevues semi-structurées ont eu lieu auprès de 7 finissants du programme EAP actuellement inscrits dans différentes facultés d'une grande université canadienne. L'analyse des données d'entrevue a indiqué que les finissants trouvaient que le programme EAP devait toucher l'acculturation sociale car ils affrontaient des barrières linguistiques et culturelles lors de leur participation à la vie universitaire après avoir terminé le programme. Les chercheurs affirment que l'acculturation sociale est généralement sous-représentée dans le curriculum EAP et que cette composante peut, par mégarde, être négligée par les enseignants et par les planificateurs et fournisseurs du programme.

As factors in facilitating student social and psychological acculturation, the role played by teachers of English as a Second Language (ESL) and the ESL instructional content they deliver are widely acknowledged. Studies across 
diverse contexts highlight the importance of both in the acculturation process (Hagan, 2004; Roessingh, 2006; Yoon, 2008). However, the function of English for Academic Purposes (EAP) instruction and instructors in these aspects of learner acculturation is less well known.

EAP instruction is a feature of tertiary studies for many international students at Canadian universities, as institutional foci of internationalization, along with linguistic and cultural diversification, create spaces for students for whom English is an additional language. Defined generally as "teaching English with the aim of assisting learners' study or research in that language" (Hyland, 2006, p. 1), the EAP curriculum typically considers academic communication as both spoken (e.g., participation in class discussions, oral thesis defense) and written (e.g., research proposals, journal articles). Acculturation into academic discourse, into the "culture" of academic ways of thinking and representing, is recognized as an important feature of EAP instruction (e.g., Cheng \& Fox, 2008). Underrepresented in EAP curriculum, however, is the role of "social acculturation," which Schumann (1986) defined as the "social and psychological integration of the learner with the target language (TL) group" (p. 379).

This research study did not set out to investigate social acculturation. Rather, the researchers' inquiry centred on post-EAP learner perceptions of curriculum: in what ways (if any) did students view EAP instructional content to align with the demands of their present undergraduate studies? Yet, analysis of interview data collected from study participants highlighted elements of Schumann's conception of social acculturation as a perceived need in EAP curriculum, as international students described the linguistic and cultural barriers they faced attempting to participate in university life post-EAP.

\section{Literature Review}

\section{Constructive Alignment}

As noted above, the researchers' initial line of investigation set out to consider if, or to what extent, students perceived the EAP curriculum to align with the linguistic demands of their current undergraduate studies. The guiding framework in the initial phase of data collection was Biggs's (1996; see also Biggs \& Tang, 2007) constructive alignment (CA). Biggs's CA includes three key features: intended learning outcomes, teaching/learning activities, and assessment tasks. The "constructive" part refers to the students' construction of meaning through appropriate learning activities. Meaning is not simply transmitted to students; rather, students have to create meaning for themselves (Biggs, 2003). The "alignment" aspect refers to what the teacher does, which is to align teaching methods and assessment tasks to the learning activities that are a part of the intended learning outcomes (Biggs, 2003). The teacher also creates an environment that supports optimal learning. When 
these three features are intentionally aligned, intended learning outcomes are met to a higher degree, and students take a deep approach to learning (Biggs \& Tang, 2011). Biggs and Tang (2011) note that while such a framework for course design should be intuitive, practices in higher education often say otherwise.

Biggs's CA framework has been applied to a wide spectrum of research into higher education curriculum design, to a range of academic fields as diverse as marketing and microbiology (Kuhn \& Rundle-Thiele, 2009; Wang, Schembri, \& Hall, 2013), and to intersections with other educational indicators (e.g., engagement, assessment, and learning environment). This present study was concerned in particular with student perceptions of CA, an element also present in the literature (e.g., Harvey \& Baumann, 2012; Lizzio, Wilson, \& Simons, 2002).

Despite the purported role of EAP in foundational preparation for university studies, a survey of the literature reveals only a small number of studies with a direct application of CA to EAP instructional design. Mavor and Trayner (2001), for example, applied CA, among other frameworks, to course design in a tertiary English for Specific Academic Purposes (ESAP) context. Although the term CA was not used in studies by James (2010a, 2010b), "transfer climate" in an EAP context was considered, as well as the extent to which learners transferred understanding to degree studies. James concluded that such transfer happens but is dependent upon multiple factors, including instructor support, student perception of transfer support, and issues related to the specific skill being transferred. Given that EAP's raison d'etre is language preparation for university study, ensuring close alignment between the two would seem a high priority.

\section{Social Acculturation in EAP}

Schumann (1986) argued that identification with the culture of a target language is a central element in language acquisition. The degree to which identification and psychological integration with the target culture occur is an important predictor of target language acquisition. Successful acquisition of the target language requires identification and social involvement with the culture in which the target language is situated (Jiang, Green, Henley, \& Masten, 2009). Schumann's hypothesis has found support in studies that have identified a correlation between levels of social integration and language proficiency (e.g., Jia, Gottardo, Koh, Chen, \& Pasquarella, 2014; Lybeck, 2002; Masgoret \& Gardner, 1999). Given the considerable empirical support for the role of social acculturation in language acquisition, its general absence from EAP syllabi is noteworthy.

As discussed earlier, the interview data revealed previously invisible concerns by students that represent aspects of what Berry (1997) called psychological acculturation. Berry (citing Graves, 1967) distinguished between 
acculturation at the group and individual levels. At the group level, acculturation refers to a change in the group's culture, contrasted with acculturation as a change in the psychology of the individual. Berry considered psychological acculturation to encompass "learning a new behavioural repertoire that is appropriate for the new cultural context" (p. 13). For the purposes of this study, the researchers prefer the term "social acculturation" to describe the need expressed by students to fit in to the social domain of university life. This social element, which we argue is largely absent from EAP curriculum, is distinguished from academic acculturation (e.g., Cheng \& Fox, 2008), which often figures prominently in EAP programming.

Research into the function of EAP in this regard is largely absent from the literature. Certainly, studies of the integration of international students studying at English-speaking universities have revealed adjustment factors. Specifically related to the effects of English language proficiency on adjustment to university life, Andrade (2006) found international students generally felt comfortable interacting with native English speakers and nonnative English speakers, although they expressed reluctance in interacting with the former due to perceived weaknesses in their own speaking skills. In Cheng and Fox's (2008) investigation of academic acculturation and the role of EAP, study participants commented that they needed help in learning how to make friends with Canadians and how to communicate naturally with them. Myles and Cheng (2003) found that the international graduate students in their study at times felt like "outsiders" and preferred to socialize with other international students (p. 258). Other studies related to the adaptation process of international students studying at English-speaking universities have addressed acculturative stressors. International students experience psychological and cultural challenges when living and studying away from their familiar surroundings, families, and friends. Yeh and Inose (2003) found that higher levels of English fluency and social connectedness were indicators of lower acculturative stress.

The research questions investigated in the current study were as follows:

1. Do former EAP students perceive alignment between their EAP curriculum and their postsecondary studies?

2. In which curricular areas and classroom activities do they perceive alignment or misalignment?

\section{Method}

The context for this present study is a large Canadian university that offers an EAP program for students unable to meet the institution's English language proficiency requirements. The EAP program typically provides English language instruction at three levels; students who complete the third level with a grade of at least $70 \%$ are deemed to have satisfied the institutional prerequisites for proficiency in English. Each level consists of three non-disci- 
pline-specific, skill-based courses centred on academic writing and grammar, reading comprehension and proficiency, and listening comprehension and oral competency, together comprising 20 hours of classroom instruction per week. The results of a placement test group students into appropriate EAP levels. Typically, most of the students in the program are international students, with a minority consisting of immigrants to Canada seeking university entrance.

\section{Participants}

Seven former EAP students (6 females and 1 male) gave consent to be recorded in semistructured interviews that explored their views on the alignment of EAP with their current university program of study. The participants represented five nationalities: China (2), Japan (2), Malaysia, Panama, and the Philippines. Six were international students, while one was a new immigrant to Canada; programs of study ranged across faculties, encompassing Business (1), Chemical Engineering (1), Fine Arts (1), International Relations (2), and Arts (2).

\section{Procedures}

Prior to undertaking the study, the researchers consulted with senior colleagues regarding the scope, aims, and ethical considerations of the proposed research and, after incorporating their feedback, applied for and received approval to conduct the study from the institution's Research Ethics Board. Following Wengraf's (2001) model, interview questions were designed around a central research question and four theory questions (see Appendix). The researchers opted for a semistructured interview format to allow participants the opportunity to contribute unanticipated content to the study, both generating meaning and critical reflection, while providing structure adequate to explore the topic under investigation (Galletta, 2013). Study participants were recruited through the assistance of the student-run EAP Alumni Association via an advertisement on the Association's social media pages and subsequent word of mouth. The interviews were recorded as MP3 files (average length 19:06), then transcribed.

Grounded theory approaches to analysis (Corbin \& Strauss, 2008; Silverman, 2014) were employed to identify common themes from the interviews. Analysis proceeded from the identification of thematic coding in singular interviews to their intersection across multiple interviews; these were then assigned broader categories as codes were clustered. The researchers' interaction with the data was characterized by the uneven and "bumpy" process described by Galletta (2013, p. 128): the researchers engaged in a process of examining and reexamining the data, in both oral and transcribed form, and evaluating and reclustering thematic codes, all the while continuing to refocus on the research questions. 


\section{Results}

Students identified areas of both alignment and misalignment between the EAP curriculum and their present undergraduate studies. A theme emerging consistently across the data was that while the explicit curriculum called for the academic emphases usually associated with EAP, study participants, while affirming (most of) its elements, identified an overlooked aspect of curriculum: social and cultural identification with local students. Findings regarding expressed areas of alignment, misalignment, and social acculturation are presented in the following sections.

\section{Expressed Areas of Alignment}

Interview data coding revealed several areas of alignment between the EAP curriculum and the students' current undergraduate studies, which can be broadly grouped under the categories of group work, writing, and note taking. Some features of speaking (e.g., group discussions, pronunciation) were shown to align, while others were perceived to be misaligned.

\section{Group work}

Group work is a common mode for organizing EAP classroom interaction, increasing the amount of time students speak to each other, giving students opportunities to share ideas with different classmates, and encouraging teamwork among the members. In the interviews, the importance of group work in EAP was a consistent theme. Student 005 commented that studying with a variety of different classmates in EAP helped her become more culturally aware and that this positively affected her communication with them.

Student 005: Yeah, 'cause you, like, in EAP you meet a lot of people from like different backgrounds, right? And then, by knowing them, you learn more. And then, by like knowing those skills you can like OK so this is a person from like say Asia you can talk about some certain kinds of topics, right? Or you can do this, and then that's actually um interesting. When I was doing like um some uh um group work, when I was doing EAP, with people from different countries, OK, like I don't do this, I can't talk about this, so yeah, this kind of helped too ... because there's most of them are international students, right? And then, for example, back in, like I'm from Pan - OK, can I say that? OK, I'm from Panama, right, and then like um our way of um working together is different from someone who is from here or someone who is from China, right? So, learning that is different, is actually helpful too. ${ }^{1}$

This same student also felt that group work in EAP helped her develop skills for listening to and working with a wide variety of classmates. 
Student 005: And then there's also presentations um 'cause you have to learn how to do group works when you are in university. Most of my um classes we have to use we have to do um group works. And then learning since I did like EAP, and then like OK so this is the person that I have to work with so I it isn't only my ideas but also include his ideas.

Another student thought that the group work he did in EAP prepared him well for university group work, which requires full commitment and participation by group members in order to complete the task.

Student 002: Yes. I think it's helpful because everyone has their life, and then but you gotta get together and get the project done. So it's like you can't ditch people like that. It's not good. So I really think that group work in EAP is really helping me.

\section{Writing}

Students commented that practicing specific academic writing skills in EAP was very helpful for immediate and future writing assignments.

Student 004: When it comes to our writing exercises and activities then to think for a topic sentence, is very important to have your title and then just to where your introduction will be written and then to be connected with your body is I found those things really significant in whatever assignments I have right now and major papers that I need to do ...

Student 004: So right now that I'm doing my assignments, especially in making the thesis statements, I've learned a lot from my EAP courses. Uh how really to formulate those thesis statements and how to develop your paragraphs from one body to another, that it is really concise, and it is connected.

Student 005: and then like how I conclude that like the whole and how coherent it was also.

Student 005 also noted that editing practice in EAP was extremely helpful in getting high marks in her current business classes.

Student 005: And how I learn also in EAP 3 how to edit my work, so that helps me a lot, and then that's actually um how I got higher marks than the native Canadians actually. For my ... personal reflection paper with my visions and mission statements, I got like 13 out of 15 whereas my group mates got like 9 out of 15 and then they're native Canadians. 
Though the ability to correspond formally and politely with professors in university was deemed important, many students found this type of e-mail communication difficult, both because they were unaware of how register and formality function in English writing, and they were unclear on how to familiarize themselves with it. Such challenges may extend to participation in online discussion forums as well, where international students may be unaware of linguistic norms in such environments. One student commented that her EAP writing class helped her learn how to write formal and polite e-mails and that this had proven useful in communication with professors in her current studies. Without this instruction, she would have had to figure it out on her own.

Student 003: Well ... writing a letter to professor to request something, it's helpful. I mean I learned how to write a letter, in a formal way, in a polite way. I remember [name of EAP teacher] taught me in class. Yeah, it's really helpful. Otherwise I have to Google online and see how I can be formal. And sometimes I will be struggle with if it's right, if it's correct. Yeah.

\section{Note taking}

Note taking represented another area of alignment between EAP and current university studies. Note taking is an important strategy for organizing and retaining information in academic lectures, and it facilitates the learning process. Student 003 noted that the note taking style she learned in EAP was an effective learning strategy that she still uses in her current studies.

Student 003: I remember [EAP teacher name] he taught us how to make a good notes. It's really helpful. [Interviewer A: Do you still use that style?] Yes, I still use it. [Interviewer A: What is that style?] It's pretty clear, like you have different shapes, bullets, and if the main topic, you use a circle, you don't go straight, you kind of go ... [Interviewer B: Like an outline.] Yeah, exactly. You use different color of pens to make small notes. On the sides, on the top ... you use arrows, it's pretty important. It's very organized. I think it's helpful.

Student 004 agreed that learning how to take organized notes in EAP had proven to be a useful skill in undergraduate work.

Student 004: I have learned taking down notes in a proper way or somehow more organized that was so helpful and we were taught about it in the EAP program. That skill is very important for me right now.

In her comment, Student 005 added that learning how to take good notes in EAP had helped because some of the professors in her program did not post Powerpoint slides. 
Student 005: And then it's actually helpful for me 'cause sometimes there are profs that they are so lazy they don't post uh PPT so you have to like oh speed like everything, then you just write whatever you read like um here and or you just like OK just write down the important parts and then that's something that is actually useful for me.

\section{Speaking}

For some students, speaking was another area of perceived alignment. Student 003 said that EAP speaking classes helped a lot because, in her view, "it's very important to be communicated with others." This same student commented that it is very important to practice speaking after class and lamented the fact that some of her classmates chose to speak their native language rather than English outside the classroom.

Student 003: And also it's very important to practice after class. Some students they would just stick with their native friends so they speak their own languages, they don't practice at all. In class we only have 30 minutes or one hour maximum to practice speaking. It's not enough at all. We should speak all the time English.

Student 002 commented that his EAP speaking and listening class was helpful. His comment suggests that pronunciation instruction helped identify difficult sounds, and presumably made him aware of how to produce them.

Student 002: I think everything is helping. I really enjoyed studying in EAP because I learned a lot and then I got some really good friends. And then speaking and listening class also really helpful. Yeah. Speaking too, yeah. Especially "th" sound. For Chinese people, we usually can't pronounce like "th." Yeah.

\section{Expressed Areas of Misalignment}

Interview data coding also revealed several areas of misalignment, which can be broadly grouped under the categories of speaking, assessment, vocabulary, and reading.

\section{Speaking}

Student 007 spoke of the challenges for international students when it came to participation in group activities.

Student 007: I have so many group work, so group work needs quick response and then of course I'm international student so I have problem and then like English is not really like native, so sometimes like really you know I can't enter the I can't join the group ... But in the 
lecture or their group work there's many students speak English very well because of native so they speak very well and very fast quick and sometimes I can't join.

The interviewer probed further, asking whether preuniversity EAP courses could prepare them for situations like these. The student's response highlighted a feature of some EAP programs, in which English language learners (ELLs) are exposed only to other ELLs.

Student 007: Maybe international student know the how feeling, and also every student learning English, so they know. But maybe we have to like we supposed to speak Canadian student native students in EAP like maybe [laughter] we I need I supposed to practice more like yeah with Canadians only native students.

Here, the EAP curriculum is portrayed as inadequate preparation for a common feature of Canadian university life: participation in small group assignments and discussion.

Assessment

Assessment represented another area of perceived misalignment between preuniversity EAP studies and tertiary mainstream requirements. Student 004 noted that a high score for essay writing in EAP did not correspond with grades of D and C received in a later English writing course. "So I was surprised that it was and then in that time I was like was EAP a good choice? Was it helping me when I had like the [low] grade?"

The same student experienced a similar incongruity between skills presumed to be achieved at a given EAP course level, instructor-assigned grades, and faculty requirements. While receiving a passing grade for the final EAP course, the student was denied entrance to a faculty and wondered what an EAP grade actually represented and whether such distinctions were arbitrary: "Because in my in my understanding too ah in if you have also good grades in your EAP 2, so it means that you have the skills, right?"

\section{Vocabulary}

Interestingly, vocabulary was an area perceived by students as lacking alignment with post-EAP tertiary studies, a finding disconcerting to the first researcher, who himself invests considerable effort in promoting vocabulary acquisition to students as a key language learning strategy. Student 001 asserted that "memorizing vocabulary is not a good way to learn like in any languages including English ... basically I think people memorize it and then forget it right away." Student 003 contrasted the importance of self-study with what she experienced in classroom vocabulary instruction:

Student 003: I think the class is how to inspire the students to be interested in learning a language, not just telling them what the mean- 
ing of the vocabularies. If they are interested in it, they would spend time learning it after class.

Another exchange (with Student 005) highlighted an area of misalignment when it came to relevant vocabulary.

Interviewer A: Is there anything in EAP that you studied that you feel is not very helpful now in your studies?

Student 005: My vocabulary. I think I mean like those words that I studied before like I don't use them, to be honest. Yeah. Just that.

Interviewer B: You studied words in vocabulary in EAP that you don't use now.

Student 005: Yeah, I don't use them. 'Cause, it's not in my field, right? It's not in Business. Yeah. 'Cause those are more like um Humanities kind of like um related topic so yeah, I don't use them now.

\section{Reading}

The theme of (ir)relevancy to current studies extended to the area of reading, as well. Student 007 described a novel she had read in EAP as "not helpful ... 'Cause totally different from Economics and in the book, and then usually we read uh like some stories from novels, but we maybe you know the academic and novel is totally different, I guess." Another interviewee echoed this concern and felt that the delivery of EAP reading instruction was also "not helpful," given the gap between the sheer volume of reading required in university studies compared with the relatively short EAP reading passages. She suggested an alternative: "So, if it's possible like teach us how to quick reading or how summarizing quickly that's more helpful for the student."

\section{Areas of Acculturation}

The friendships made with classmates from all over the world in EAP classes was a common theme in the interviews.

Student 002: And then um because EAP program it's multicultural class, right, there is zero tolerance for like racist and discriminations. That's what I learned from EAP as well. Because my year, there were so many different people from different country. We get along really good. We didn't have fight. We are good friends still now. So ... it's pretty good.

Another student commented that a strong accent may be a barrier to making Canadian friends and suggested pronunciation instruction for incoming EAP students.

Student 001: Then I think listening to English like um often would 
be very helpful even because um I think reducing accent is very important for international students because when they have too um accent that is too strong it always um reduce what they always lose opportunity ... I think it matters ... and also when making friends if your accent is too hard to understand, you'll be hard to make friends. Yeah and I think reducing accent is very important for them.

Student 003 suggested using class time to focus on using English in reallife situations rather than relying too much on textbooks.

Student 003: I think in class we should focus on how to use English in real life comfortable and confident when they speak English actually, less focus on, they look at the textbook. We spend time at home looking at the textbook by himself. Should make the class more interesting, more fun.

Student 003 also noted that learning Canadian words in her EAP speaking class had had positive effects on how her Canadian classmates in her current studies perceived her.

Student 003: I remember [name of EAP teacher] taught us some Canadian words make me sound more like Canadian when I talk to my classmates. And actually they don't think they don't know I was international student until I unless I told them. So I think it's very cool to sound like a Canadian. Yeah.

The above extracts illustrate an expressed desire of learners for practical preparation for the social domain of university studies. Students did not discount the more "academic" content of EAP, but their comments suggested that social acculturation is a critical aspect of EAP instruction, which, in their experience, was missing.

\section{Discussion}

As noted previously, students generally perceived the EAP curriculum as aligning with the needs of their current undergraduate program. EAP instruction in writing (whether essay structure, formal register, or note taking) and group discussion figured centrally in this regard. Areas in which students perceived a lack of alignment between the requirements of their university studies and their prior tuition in EAP included opportunities for speaking practice with local students, areas of assessment, vocabulary learning, and reading texts which students believed to be unrelated to present study needs.

Noteworthy in the data was the expressed desire of students for an element of curriculum that, the researchers assert, is often overlooked by EAP curriculum planners and instructors alike: the central role of social and psy- 
chological acculturation in university life. The role of academic acculturation figures in the literature on EAP curriculum (e.g., Cheng \& Fox, 2008; Dooey, 2010). Although acculturation into the target culture features in discussions of ESL instruction, the researchers have found this subject curiously absent from the literature on EAP curriculum.

Our data support the inclusion of social acculturation in the EAP curriculum. While not discounting the value of more "academic" elements of the explicit curriculum, study participants expressed a felt need for social and cultural interactions with local students to be included in curriculum considerations. One example, noted previously, was Student 003's desire to "sound like a Canadian." Another example of a felt need for identification with local students was expressed by Student 007.

Interviewer B: So when you're in group work and there are some Canadian students and they are talking fast, you feel you can't join in.

Student 007: So ... mmm ... sometimes like they really like, "Okay you're international student, go away," like, I will do that ... so I just listen and then first time I couldn't but after that I asked my TA and then they have like question sheet, so I just get question sheet before the group work and then just read and then search and then join them.

Interviewer A: So you're preparing for joining the group.

Student 007: Yeah, I have to, actually.

Interviewer B: How do you feel when they are talking fast and you don't understand? How do you feel?

Student 007: Really, I want to join them. Like, same group, same group members so I really want to join them. I want to say my opinion. But, first time, it was really like I can't join ... oh what should I do, but TA [the teaching assistant] is really helping me.

In the researchers' experience, the structure of EAP programming, as usually conceived, severely limits opportunities for the types of acculturation that students identified. Traditionally, cloistered EAP classes of international students provide few opportunities for authentic interaction with mainstream university learners, despite, as Student 007 explained, the importance for such interactions in post-EAP university courses. Top-down generated social opportunities provided by the university for international students (perhaps assumed to be a monolithic, homogeneous group?) rarely promote communicative interaction with local students, either.

Student 001 expressed this need plainly:

Student 001: Yup. My suggestion, it may be hard, but my suggestion will be like maybe the [Faculty of] Education students to interact 
with EAP students so I think um ... it will be beneficial for both um

... Canadians and foreign students.

This insightful comment is consistent with the findings of Trice (2004), Cheng, Myles and Curtis (2004), and others who recommend planned, intentional facilitation of interaction between international and local students. Such initiatives, of course, require allocation of resources not always prioritized in postsecondary budget planning; however, future research might investigate whether these types of intentionally facilitated interactions result in positive learning outcomes for international students. The researchers wonder whether the inclusion or exclusion of activities geared to psychological and social integration reflects a perceived gulf between traditionally defined aims of ESL instruction and EAP. A perceived need to distinguish EAP from programming less "academic" in orientation, whether experienced by instructors, program planners, or learners themselves, is an area of investigation that could be explored in further studies.

\section{Conclusion}

This article has described a research study investigating perceptions of EAP programming as it relates to student needs in undergraduate studies. While the small sample size $(n=7)$ and the fact it was drawn from only one EAP program call for caution when considering the wider generalizability of the findings, the data revealed areas of both alignment and misalignment between EAP and undergraduate course work. A dominant theme in the data was participants' expressed desire for the inclusion of elements of social acculturation. Given that the participants in this study were all newcomers to Canada, exploring perceptions of the role of EAP in social acculturation among permanent residents (as opposed to international students) presents interesting possibilities for future research.

EAP program providers and instructors benefit at present from sophisticated research for determining curriculum content, such as the insights presented by corpus linguistics or research into genre analysis. In this environment, "soft skill" curriculum elements such as psychological and social integration seem almost out of step. Nevertheless, the findings of this study indicate that this area of curriculum, often overlooked by instructors and syllabus planners (including the researchers)-perhaps in the pursuit of more "academic" content-figured strongly in student perceptions of what ought to be included in EAP programming.

\section{Note}

1 Due to article length restrictions, student comments have been edited for repetition and length. Grammatical constructions are presented as in the original, with the goal of fidelity to student voice. 


\section{The Authors}

M. Gregory Tweedie is Academic Coordinator of the International Foundations Program, Werklund School of Education, University of Calgary. His research interests include language varieties in education, international Englishes, and intelligibility in English as a lingua franca contexts. He holds a PhD in Education from the University of Southern Queensland.

Marcia Kim is an instructor in the International Foundations Program, Werklund School of Education, University of Calgary. She obtained her MA TESOL from the School for International Training. She is also a PhD student at the University of Calgary. Her research project focuses on workplace communication of internationally educated nurses.

\section{References}

Andrade, M. S. (2006). International students in English-speaking universities: Adjustment factors. Journal of Research in International Education, 5(2), 131-154. doi:10.1177/1475240906065589

Berry, J. W. (1997). Immigration, acculturation, and adaptation. Applied Psychology: An International Review, 46(1), 5-34. doi:0.1111/j.1464-0597.1997.tb01087.x

Biggs, J. (1996). Enhancing teaching through constructive alignment. Higher Education, 32(3), 347-364. doi:10.1007/BF00138871

Biggs, J. (2003). Aligning teaching for constructing learning. Retrieved from https://www.heacademy.ac.uk/aligning-teaching-constructing-learning

Biggs, J., \& Tang, C. (2007). Teaching for quality learning at university (3rd ed.). Maidenhead, Berkshire, UK: Open University Press.

Biggs, J. \& Tang, C. (2011). Teaching for quality learning at university. Maidenhead, UK: Open University Press.

Cheng, L., \& Fox, J. (2008). Towards a better understanding of academic acculturation: Second language students in Canadian universities. Canadian Modern Language Review, 65(2), 307333. doi:10.3138/cmlr.65.2.307

Cheng, L., Myles, J., \& Curtis, A. (2004). Targeting language support for non-native English speaking graduate students at a Canadian university. TESL Canada Journal, 21(2), 50-71. doi:10.18806/tesl.v21i2.174

Corbin, J., \& Strauss, A. (2008). Basics of qualitative research: Techniques and procedures for developing grounded theory (3rd ed.). Thousand Oaks, CA: Sage.

Dooey, P. (2010). Students' perspectives of an EAP pathway program. Journal of English for Academic Purposes, 9, 184-197. doi:10.1016/j.jeap.2010.02.013

Galletta, A. (2013). Mastering the semi-structured interview and beyond: From research design to analysis and publication. New York: New York University Press.

Hagan, M. (2004). Acculturation and an ESL program: A service learning project. Journal of Multicultural Counseling and Development, 32, 443-448.

Harvey, M., \& Baumann, C. (2012). Using student reflections to explore curriculum alignment. Asian Social Science, 8(14), 9-18. doi:10.5539/ass.v8n14p9

Hyland, K. (2006). English for academic purposes: An advanced resource book. London: Routledge.

James, M. A. (2010a). An investigation of learning transfer in English-for-general-academicpurposes writing instruction. Journal of Second Language Writing, 19(4), 183-206. doi:10.1016/j. jslw.2010.09.003

James, M. A. (2010b). Transfer climate and EAP education: Students' perceptions of challenges to learning transfer. English for Specific Purposes, 29(2), 133-147. doi:10.1016/j.esp.2009.09.002

Jia, F., Gottardo, A., Koh, P. W., Chen, X., \& Pasquarella, A. (2014). The role of acculturation in reading a second language: Its relation to English literacy skills in immigrant Chinese adolescents. Reading Research Quarterly, 49(2), 251-261. doi:10.1002/rrq.69

Jiang, M., Green, R. J., Henley, T. B., \& Masten, W. G. (2009). Acculturation in relation to the acquisition of a second language. Journal of Multilingual and Multicultural Development, 30(6), 481-492. doi:10.1080/01434630903147898 
Kuhn, K. L., \& Rundle-Thiele, S. R. (2009). Curriculum alignment: Exploring student perception of learning achievement measures. International Journal of Teaching and Learning in Higher Education, 21(3), 351-361.

Lizzio, A., Wilson, K., \& Simons, R. (2002). University students' perceptions of the learning environment and academic outcomes: Implications for theory and practice. Studies in Higher Education, 27(1), 27-52. doi:10.1080/03075070120099359

Lybeck, K. (2002). Cultural identification and second language pronunciation of Americans in Norway. Modern Language Journal, 86(2), 174-191. doi:10.1111/1540-4781.00143

Masgoret, A., \& Gardner, R. C. (1999). A causal model of Spanish immigrant adaptation in Canada. Journal of Multilingual and Multicultural Development, 20(3), 216-236. doi:10.1080/01434639908666378

Mavor, S., \& Trayner, B. (2001). Aligning genre and practice with learning in higher education: An interdisciplinary perspective for course design and teaching. English for Specific Purposes, 20(4), 345-366. doi:10.1016/S0889-4906(01)00025-4

Myles, J., \& Cheng, L. (2003). The social and cultural life of non-native English speaking international graduate students at a Canadian university. Journal for English for Academic Purposes, 2(3), 247-263. doi:10.1016/S1475-1585(03)00028-6

Roessingh, H. (2006). The teacher is the key: Building trust in ESL high school programs. Canadian Modern Language Review, 62(4), 563-590. doi:10.1353/cml.2006.0039

Schumann, J. H. (1986). Research on the acculturation model for second language acquisition. Journal of Multilingual and Multicultural Development, 7(5), 379-393. doi:10.1080/01434632.19 86.9994254

Silverman, D. (2014). Interpreting qualitative data (5th ed.). Los Angeles: Sage.

Trice, A. G. (2004). Mixing it up: International graduate students' social interactions with American students. Journal of College Student Development, 45(6), 671-687. doi:10.1353/ csd.2004.0074

Wang, J. T. H., Schembri, M. A., \& Hall, R. A. (2013). How much is too much assessment? insight into assessment-driven student learning gains in large-scale undergraduate microbiology courses. Journal of Microbiology and Biology Education, 14(1), 12-24. doi:10.1128/jmbe.v14i1.449

Wengraf, T. (2001). Qualitative research interviewing: Biographic narrative and semi-structured methods. London: Sage.

Yeh, C., \& Inose, M. (2003). International students' reported English fluency, social support satisfaction, and social connectedness as predictors of acculturative stress. Counselling Psychology Quarterly, 16(1), 15-28. doi:10.1080/0951507031000114058

Yoon, B. (2008). Uninvited guests: The influence of teachers' roles and pedagogies on the positioning of English language learners in the regular classroom. American Educational Research Journal, 45(2), 495-522. doi:10.3102/0002831208316200

\section{Appendix \\ Central Research Question (CRQ), Theory Questions (TQ), and Interview Questions (IQ) (Wengraf, 2001, p. 81-92)}

CRQ: How do EAP graduates perceive (mis)alignment between EAP curriculum and their current program of study?

TQ1: In what ways do study participants perceive EAP learning activities as aligned with the demands of their current university studies?

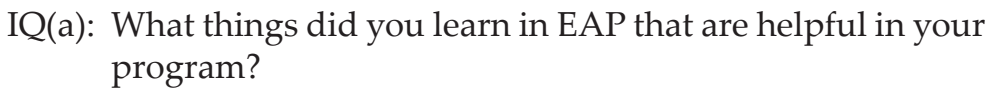


$\mathrm{IQ}(\mathrm{b})$ : What things did you study in EAP that are not helpful in your program?

TQ2: In what ways do study participants perceive EAP assessment activities as aligned with the demands of their current university studies?

IQ(c): Think about the things you were tested on in EAP. How have these things helped you in your program?

TQ3: To what extent did instructor expertise and pedagogy align with postEAP studies?

IQ(d): What things did your EAP instructor do in class that have been helpful in your program?

IQ(e): What things did your EAP instructor do in class that have not been helpful in your program?

TQ4: What input do post-EAP students suggest for future curriculum alignment?

IQ(f): We are evaluating our EAP curriculum to make it as useful as possible for students beginning their university studies. What advice would you give us? 